\title{
The Archives of American Mathematics
}

Carol Mead (University of Texas at Austin, USA) and Albert C. Lewis (The Initiative for Mathematics Learning

by Inquiry, Austin, USA)

The Archives of American Mathematics (AAM) was established by an agreement between the Mathematical Association of America (MAA) and the University of Texas at Austin in 1978. It was formed not only as the official repository for the association but also to serve as a nucleus for additional gifts of mathematical archival material. It has since become a de facto national centre for original sources in the history of mathematics, accepting personal and institutional collections. It also encourages other archives to offer homes for collections relating to the mathematical sciences.

\section{Origin of the AAM}

An American researcher using the archives at Göttingen described earlier in the EMS Newsletter (Rowe 2016) will be impressed with the richness of its representation of the principal mathematicians who helped make Göttingen the centre of the mathematical universe in the 19th century, including Gauss, Riemann, Klein, Dedekind and Hilbert. That researcher might wish that there were an equally rich collection for American mathematicians who brought the United States to modern prominence. For this early period in the US, the publications of historians, especially Parshall and Rowe (1994), demonstrate that substantial original sources do exist for exploring the lives and works of the most prominent mathematicians, such as Benjamin Peirce, J.W. Gibbs, E.H. Moore, J.J. Sylvester, O. Veblen, R.L. Moore and G.D. Birkhoff. However, of these mathematicians, it can be argued that only Veblen and R.L. Moore are represented by collections comparable to those in Göttingen with respect to the depth and breadth of coverage of their life and work. The Veblen collection is at the Library of Congress in Washington, D.C., and R.L. Moore's is at the University of Texas at Austin. It is the latter collection that formed the starting point for the AAM.

For most of the first half of the 20th century and somewhat beyond, the University of Texas mathematics department was dominated by R.L. Moore (1882-1974). Renowned as a mathematician, he became even better known for his method of teaching, often called the "Moore method". His students became the leading set theory topologists of the century and perhaps the most distinguished group of research mathematicians to be taught by one professor (Parker 2005). After his death in 1974, his extensive "papers" (to use the common but ambiguous American archival term), or Nachlass, were preserved at the university and an effort was made to see that the Nachlass of his students was also preserved, if not at Texas then at least at suitable institutions elsewhere. Several of his students had been presidents of one or both of the major mathematical organisations: the Mathematical Association of America (MAA) and the
American Mathematical Society (AMS). One of these students, R.L. Wilder, who had been president of both groups and who was a mathematician as well as an historian, pointed out that neither of these organisations had an archival repository for preserving their history. He received a positive response from Texas when he suggested that perhaps they would be interested in being that repository.

Others in the mathematical community picked up the cause and, though only the MAA agreed to make Texas their official archival repository, the AMS arranged a separate agreement with Brown University, a neighbour of the society in Providence, Rhode Island. Inspired by this activity, the American Statistical Association formed an archival agreement with Iowa State University not long afterward.

Today, with nearly 130 collections of papers and records of mathematicians and mathematical organisations, the AAM offers an abundance of potential avenues for research. Culture, art and organisational history, among others, have all been explored in the collections. In pursuit of these topics, the archives primarily attract historians of mathematics focused on the history of American mathematics and mathematicians, and their influence and roles in society. As a part of this, the collections reflect the vital influence that European mathematicians had on developments in the USA.

\section{European connections}

Among Hilbert's correspondence at Göttingen are letters from 1900 to 1906 from George Bruce Halsted, R.L. Moore's mathematics professor at Texas. Most of Halsted's original letters no longer exist but he did write to Moore that he had sent a copy of his book, Rational Geometry: A Textbook for the Science of Space; Based on Hilbert's Foundations (Halsted 1904), to Hilbert. Since the book was dedicated to Hilbert, who had politely given his approval for Halsted's project, Hilbert gave it to his assistant Max Dehn to review. Dehn published a severe criticism of it, particularly focusing on the textbook's results that depended on continuity, in spite of Halsted's explicit statement that he was not assuming the Archimedean axiom.

While Europe has largely been able to retain a rich archival history in modern times, wars have taken their toll. Hermann G. Grassmann (1809-1877) is an example: his Nachlass was listed in his Gesammelte mathematische und physikalische Werke (1894-1911) but then apparently lost during World War I (Petsche et al. 2009). Much of Cantor's Nachlass met a similar fate around the time of World War II, as is mentioned by Rowe. What exists from this period is often fragmentary and scattered. This, perhaps not unexpectedly, is the case for Max Dehn, given 
his torturous journey after leaving Germany in 1939 before eventually settling in the USA. Prior to leaving Germany, Dehn taught at Frankfurt University, where one of his students was Wilhelm Magnus, who received his degree in 1931. As indicated in Rowe (2016), Magnus encouraged Dehn's widow, Toni, to deposit whatever papers she had of her husband in the archives. The contents range from 1900, when he was at Göttingen, to 1950, when he was living in the USA in North Carolina. Many of the documents are in German, though some are in English, and include lectures he delivered, as well as correspondence, manuscripts, original drawings by Dehn, published works by him and others and a few photographs. It includes correspondence with Helmuth Kneser, items relating to Ernst Hellinger and C.L. Siegel, and single letters from Emmy Noether, Ernst Zermelo and Leo Frobenius, to mention just a few names.

Other collections of Dehn's papers in the USA, of varying sizes and dates, can be found, for example, in the Western Regional Archives in North Carolina, the Idaho State University in Pocatello and the Library of Congress, where Oswald Veblen's papers contain two folders of Dehn's documents.

What is interesting about the Texas collection is the broad coverage of Dehn's life and his interest in the intersection of art and mathematics. Marjorie Senechal (a professor emerita of Smith College and Editor-in-Chief of the Mathematical Intelligencer) and Philip Ording (a professor at Sarah Lawrence College) are collaborating with a group of about 12 mathematicians and historians of mathematics to write a composite biography of Dehn.

In an email to one of the authors, Senechal described the AAM collection, compared to others in the USA, as providing "a deeper, broader, richer picture, of Dehn the mathematician, Dehn the teacher, Dehn the father of three children, and his and [Toni's] journey across America, from San Francisco to Black Mountain College" (Senechal 2017). With this broader understanding of Dehn, and with information she gathered from other archives, Senechal proposes to write about the Dehns' journey.

In a talk at an Oberwolfach mini-workshop in 2016, Senechal described the Dehns' adventures in America starting from their arrival to its shores. They landed in San Francisco, California, on 1 January 1941, after escaping Nazi Germany via Oslo, Siberia and Japan. From there, the Dehns' already-uprooted lives continued in a similar fashion, moving from one state to another in an effort to find a more permanent home. It was not until Dehn found a teaching position at Black Mountain College in North Carolina that they settled down. There, as Senechal notes, Dehn indulged his many interests outside of mathematics by teaching ancient Greek, philosophy, elementary mathematics and a course he called "geometry for artists". Dehn retired in 1952 and died a few weeks later (Senechal 2016).

Philip Ording approaches Dehn from the perspective of art. In 2013, on a visit to the AAM, he found the "Geometry for Artists" folder, connected to the course mentioned above, to be especially inspiring. He included a drawing from the "Geometry" folder as the cover for an essay called "A Definite Intuition", which appeared in the Bulletins of the Serving Library (Ording 2013). The folder contains mathematical artwork created by Dehn and his students in 1948. As part of his description of the figure, Ording writes: "The points of the beautifully penned ellipse ... emerge not by coordinates determined by an equation, but rather by the intersections of the construction lines produced by the interaction of a pair of concentric circles".

Ernst Hellinger, another figure whose Nachlass hardly exists as a whole, is, in addition to the Dehn collection, also represented in the papers of William T. Reid. A colleague of Hellinger at Northwestern University in the 1940s and 1950s, Reid was evidently bequeathed papers that Hellinger brought with him from Germany to Northwestern in 1939, including lecture notes from his teaching at Frankfurt from as early as 1919.

A further Göttingen connection is through Isaac Jacob Schoenberg (1903-1990), who moved to the USA in 1930 with many of his personal papers, including correspondence and student notebooks from his studies at Jassy [Iaşi] in Moldavia and in Berlin and Göttingen, mainly from the 1920s. Especially interesting are the lecture notes of Edmund Landau, Harald Bohr and Issai Schur, all of whom are represented in his correspondence.

Naturally, there is correspondence with European mathematicians in the Nachlässe of other American mathematicians. At the AAM, this would particularly include Moore (corresponding with Maurice Fréchet, Bronisław Knaster, Kazimierz Kuratowski and Wacław Sierpiński) and the number theorist H. S. Vandiver (corresponding with Helmut Hasse, Erich Bessel-Hagen, Henri Fehr, Dragoslav S. Mitrinović and B.L. Van der Waerden). Also, in the pre-World War II period, R.L. Moore's students, J.R. Kline and R.G. Lubben, visited members of the Polish school of topologists in Warsaw; Lubben's group photograph of himself with Samuel Dickstein, K. Kuratowski, Kline, K. Zarankiewicz and S. Masurkiewicz must be a rare artefact from that time.

More recently, the international connections of AAM were enhanced by the addition of the Nachlass of the prolific English historian Ivor Grattan-Guinness (19412014), whose world-ranging activities give unique insight into the state of the history of mathematics in the late 20th century.

\section{American stories}

Researchers, of course, typically employ multiple collections to achieve their aims. One such researcher is Michael Barany, currently a postdoctoral fellow at Dartmouth College, whose project concerns the "history of intercontinental research and disciplinary institutions in twentieth-century mathematics". During a week-long visit to the archives, Barany surveyed three collections: the Paul R. Halmos Papers, the R.L. Wilder Papers and the MAA Records.

The Nachlass of Paul Halmos (1916-2006) alone provided several perspectives relevant to his project. The 
AAM holds his complete archive, including his papers and his photographic collection of some 14,000 images. His papers cover his long and distinguished career, revealing a level of professional involvement that is almost breathtaking in its scope: teaching (including visiting appointments in the USA and abroad), committee work, editorships, articles and books, extensive correspondence, conferences and national and international travel.

Barany was especially interested in a 1951 visiting appointment in which Halmos, along with his wife, Virginia ("Ginger"), spent a year at the University of Montevideo in Uruguay. Halmos, as was his custom, kept a diary of the excursion, which gave Barany background information that will assist him in arguing that Halmos played "an important role in the consolidation of professional mathematics in South America". Barany goes on to note that other papers in the collection will help him to explain Halmos' important role in international mathematics as it developed in the 20th century (Barany 2017).

While Wilder's career was also outstanding, he remained for most of it at one institution: the University of Michigan in Ann Arbor. Nonetheless, he "was a wellconnected participant in the major [American] mathematical organizations" (Barany 2017). Wilder, a pioneer in the field of topology, was heavily involved in numerous organisations and, as noted above, originated the idea of the AAM (Raymond 2003). Through this collection, Barany was able to "identify new consequences and connections from those [organisational] events" of interest.

For Barany, the MAA Records provided supplementary information. Both Wilder and Halmos were active participants in the MAA and contributed to its mid-century evolution and character. Surveying officer records and correspondence, he found that "these formal documents show the regular hum of activity at a prominent organization of professional mathematicians...".

Another historian of mathematics recently made a discovery that demonstrates how the AAM's archival collections may enrich our understanding of the history of mathematics and American cultural history while also demonstrating the ties among American mathematicians. As she was working with the R.L. Wilder Papers, Karen Parshall (a professor of history and mathematics at the University of Virginia) stumbled on correspondence between Wilder and an aspiring African-American mathematician, William Schieffelin Claytor. The result of her discovery is her article, "Mathematics and the Politics of Race: The Case of William Claytor" (Parshall 2015).

From the R. L. Wilder and the R. L. Moore Nachlässe, she writes a story of a "family' of topologists" and of the cultural realities of the day. Moore corresponded extensively with notable mathematicians, many of whom had been his students. Among the latter were Wilder and J.R. Kline. Kline had been Moore's first doctoral student, obtaining his degree at the University of Pennsylvania in 1916. Serving on the faculty of his alma mater from 1920 to 1955 , Kline supervised 19 doctoral students, two of whom were black.
When Claytor wrote his first letter to Wilder in 1931, he was a young graduate student at the University of Pennsylvania under Kline's tutelage. Claytor came to Kline after having earned his Master's degree under Woodard at the historically black institution of Howard University in 1930. Recognising strong potential in Claytor, Woodard encouraged him to apply to Pennsylvania's graduate programme in order to study with Kline.

By mentoring and supervising Woodard and Claytor, Kline enlarged the Moore family, though in a way in which Moore may not have approved. As Parshall notes, Moore was a "product of his time and place", which is to say that he was a dedicated segregationist from the American South. The University of Texas did not admit black people through most of Moore's long career there from 1920 to 1969.

Claytor could undoubtedly have pursued a career in research, which was his primary interest. Parshall notes that the 1920 s to the 1960s were a "golden age" in point-set topology and Claytor "contributed to enhancing its shine". Unfortunately, despite the efforts of Kline, Wilder and others, he was not inclined to risk experiencing more discrimination than he had already in other situations by following up on these efforts. He took a teaching position at Howard University in

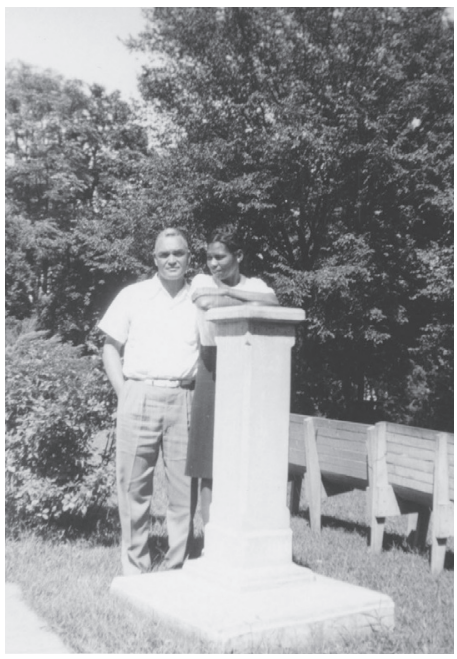

William Claytor with his wife Mae Pullins Claytor, Harpers Ferry, West Virginia, 1967. (Raymond Louis Wilder Papers, Dolph Briscoe Center for American History) Washington, D.C., and remained there for the rest of his career. He died in 1967.

Parshall shared her information about Claytor with Dr Sibrina Collins, a chemist and historian of science, technology, engineering and mathematics (STEM) at The Marburger STEM Center at Lawrence Technological University in Southfield, Michigan. Collins was writing a profile of Claytor for the online journal, Undark, which focuses on the "intersection of science and society". The resulting essay, "Unsung: William Claytor" (Collins 2016), relays Claytor's academic story beyond the mathematical community.

The huge topic of mathematics education is represented by one of the largest AAM collections, the School Mathematics Study Group (SMSG), a national education reform project launched in 1958 with a major grant from the National Science Foundation. Headquartered at Stanford University, it oversaw an extensive programme of textbook writing, teacher training and educational filmmaking, as well as promulgating, throughout the 1970s, the so-called "new math" movement. This archive has been a valuable source for researchers interested in mathematics education and its history, Phillips 
(2015) being a recent example. One of the precursors of SMSG was the University of Illinois Committee on School Mathematics led by Max Beberman. AAM has 47 film reels of his talks on teaching high school mathematics, produced in the 1950 s and viewable on the AAM website.

\section{Photographs, films, oral histories}

Images, of course, supplement published discourse in most subject areas and mathematics is no exception. Two of the AAM's oft-used collections are the Paul R. Halmos Photograph Collection and the Marion Walter Photograph Collection, both of which depict distinguished 20th century mathematicians (American and international). While Halmos' collection spans more than 9 decades from 1907 to 1998, his snapshots of mathematicians begin in 1940, when he served as John von Neumann's assistant at the Institute of Advanced Study in Princeton, New Jersey. Marion Walter's photographs span the years from 1952 to the 1980s.

As noted above, the Halmos Collection contains approximately 14,000 photographs, mostly taken by Halmos himself (though he also accumulated images from other people). In 1987, Halmos published a small proportion of his pictures in his book, I Have a Photographic Memory (Halmos 1987). He notes in the preface that "I have been a snapshot addict for more than 45 years, and I have averaged one snapshot a day". A number of his subjects, such as John Nash, were rising stars at the time Halmos captured them, while others, like Arthur Erdélyi, were in the latter years of long, successful careers.

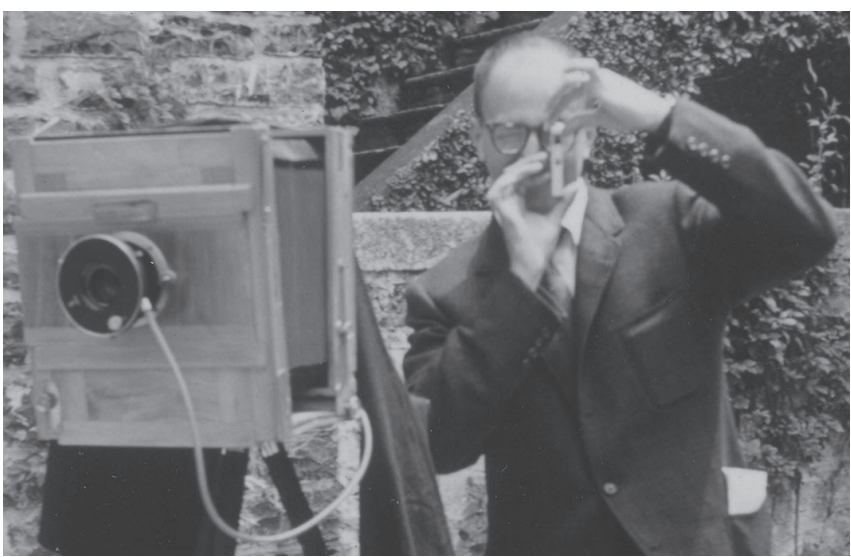

Halmos photographing himself, Varenna, Italy, 1960. (Paul Halmos Photograph Collection, Dolph Briscoe Center for American History)

Knowing that interest in the Halmos snapshots will be high, the AAM is digitising over 8,300 of them and will put them on the web. In fact, in collaboration with the MAA, 342 photographs have already been digitised and added to their online periodical, Convergence, with the title "Who's That Mathematician? Images from the Paul R. Halmos Photograph Collection" (Beery 2012).

While significantly smaller than the Halmos collection, the Marion Walter collection - with some 60 or so images instead of thousands - contains subjects that are no less eminent. Among them are A.A. Albert, Paul Erdós, Olga Taussky-Todd and H.S.M. Coxeter.
Now retired from the University of Oregon, Eugene, Walter came to the USA in 1948 from England, where she, her sister and her parents had lived after escaping Nazi Germany in 1939. Walter then pursued her mathematical degrees, first a Master's of science in 1954 from New York University and eventually her PhD in 1967 from Harvard University. George Pólya influenced her interest in education and he became one of her teachers at Stanford University, where she held a fellowship in 1960.

Walter took her photographs during various events that she attended between the 1950s and the 1980s. For example, in 1952, she attended the Institute for Numerical Analysis at the University of California, Los Angeles, where she snapped Ernst G. Straus, and went for tea at the home of Alexander Ostrowski, whom she also photographed. At a picnic in 1953 with other mathematicians from New York University, she captured Fritz John and Wilhelm Magnus and, during her stay at Stanford, she took a snapshot of Pólya.

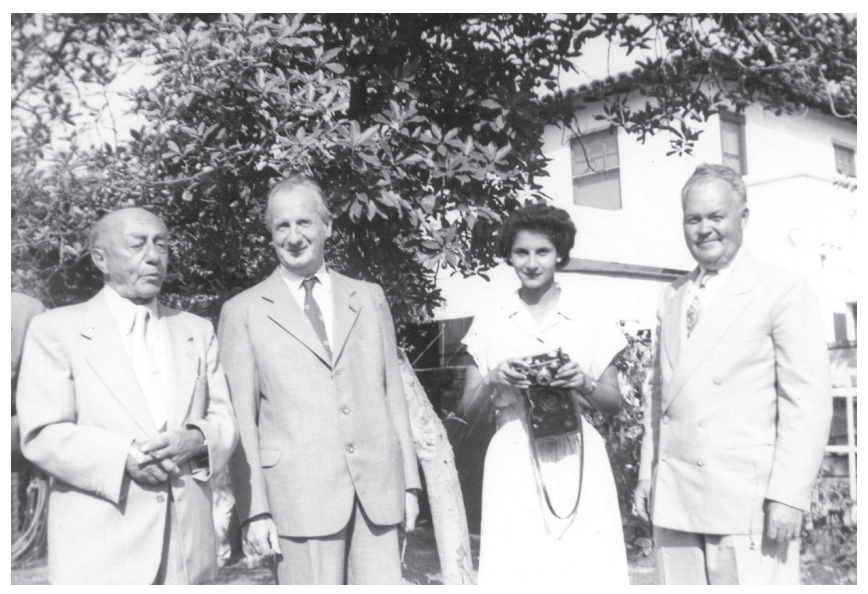

Left to right: Tobias Danzig, J.G. van der Corput, Marion Walter and Magnus Hestenes at a tea party at the home of Alexander Ostrowski, Los Angeles, CA, 3 August 1952. (Marion Walter Photograph Collection, Dolph Briscoe Center for American History)

Both Halmos and Walter captured mathematicians (both well known and less well known) during unscripted moments: at conferences, chatting at parties, teaching a class or sitting around a pool. In the same informal, personal vein, the AAM has several hundred voice and video recorded interviews with mathematicians, which are the product of a number of projects. They bring the history of mathematics to life. Indeed, this is true for all the AAM's collections.

The AMS-MAA Joint Archives Committee acts as an unofficial liaison between the AAM and the two mathematical organisations. It has encouraged the preservation of Nachlässe and has promoted the awareness of archives, for example, through the committee project (Batterson et al. 2003). The AAM has been supported by the University of Texas at Austin through its Briscoe Center for American History, where it is housed and made available, and also through generous seed-money grants from the Educational Advancement Foundation.

To learn more about the AAM's Nachlass, please visit: http://www.cah.utexas.edu/collections/math_finding aids.php. 


\section{References}

Barany 2017: Michael J. Barany, Re: Policy Committee and Math Awareness. Email, 24 February 2017, to Carol Mead.

Batterson et al. 2003: Steve Batterson, Charles Curtis, Albert Lewis and Karen Parshall, The value of mathematical archives, Notices of the AMS, 50 (2003): 1409-1415.

Beery 2012: Janet Beery, Who's that mathematician? Images from the Paul R. Halmos photograph collection, Convergence, January 2012, http://www.maa.org/press/periodicals/convergence/whos-thatmathematician-images-from-the-paul-r-halmos-photograph-collection. Accessed 10 April 2017.

Collins 2016: Sibrina Nichelle Collins, Unsung: William Claytor, https:// undark.org/article/unsung-william-waldron-schieffelin-claytor. Accessed 10 April 2017.

Halmos 1987: Paul R. Halmos, I Have a Photographic Memory, Providence, RI: American Mathematical Society, 1987.

Halsted 1904: George Bruce Halsted, Rational Geometry; A Text-book for the Science of Space; Based on Hilbert's Foundations. New York: J. Wiley \& Sons, 1904.

Ording 2013: Philip Ording, A definite intuition, Bulletins of the Serving Library, no. 5 (2013): 34-35.

Parker 2005: John Parker, R. L. Moore: Mathematician and Teacher, Washington, D.C.: Mathematical Association of America, 2005.

Parshall 2015: Karen Hunger Parshall, Mathematics and the politics of race: the case of William Claytor ( $\mathrm{PhD}$, University of Pennsylvania, 1933), The American Mathematical Monthly, 123 (2015): 214-240.

Parshall and Rowe 1994: Karen Hunger Parshall and David E. Rowe, The Emergence of the American Mathematical Research Community, 1876-1900: J.J. Sylvester, Felix Klein and E. H. Moore, Providence: American Mathematical Society/London Mathematical Society, 1994.

Petsche et al. 2009: Hans-Joachim Petsche, Lloyd Kannenberg, Gottfried Kessler and Jolanta Liskowacka, Hermann Grassmann: Roots and Traces. Autographs and Unknown Documents. Basel: Birkhäuser, 2009
Phillips 2015: Christopher J. Phillips, The New Math: A Political History, Chicago: University of Chicago Press, 2015.

Rowe 2016: David E. Rowe, Göttingen's SUB as Repository for the Papers of Distinguished Mathematicians, Newsletter of the European Mathematical Society 101 (2016): 39-44.

Senechal 2016: Marjorie Senechal, Max Dehn's journey through America, in Mini-Workshop: Max Dehn: His Life, Work, and Influence. Mathematisches Forschungsinstitut Oberwolfach, 2016.

Senechal 2017: Marjorie Senechal, Re: Max Dehn article. Email, 5 April 2017, to Carol Mead.

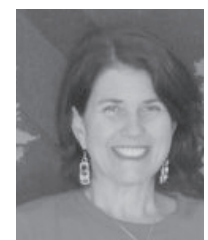

Carol Mead is the Archivist for the Archives of American Mathematics at the Briscoe Center for American History at the University of Texas at Austin. She began her career in 1999 in the Denver Public Library's archives. In 2002, she received her library degree from the University of Texas at Austin. She remained in Austin and founded the archives for a local company, National Instruments. She has been in her current position since 2007.

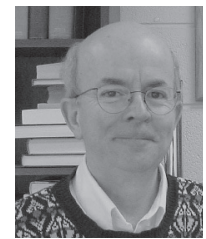

Albert C. Lewis is an historian of mathematics who has contributed to the scholarly editions of the works of Bertrand Russell and Charles S. Peirce. Soon after obtaining a doctorate at the University of Texas at Austin, he helped to found the Archives of American Mathematics. He is currently a member of the board of directors and a volunteer at a public foundation called 'The Initiative for Mathematics Learning by Inquiry'. 